\title{
PROJETOS DE INOVAÇÃO COMO MEDIADORES DA CONSTRUÇÃO DE NOVAS CAPACITAÇÕES ORGANIZACIONAIS: ANÁLISE DE UM CASO NA INDÚSTRIA DE EXPLOSIVOS PARA MINERAÇÃO
}

Larissa Pinto de Lima (limap.larissa@gmail.com) - Universidade Federal de Minas Gerais, UFMG.

Guilherme Henrique Gontijo Moreira (guilhermegontijo68@gmail.com) - Universidade Federal de Minas Gerais, UFMG.

Raoni Barros Bagno (raonibagno@dep.ufmg.br) - Universidade Federal de Minas Gerais, UFMG.

\section{RESUMO}

A criação de capacidades organizacionais para inovação é um aspecto crucial para a competitividade de empresas em diversos setores. Todavia, a literatura não aponta um caminho único para a construção de tais capacidades. Neste artigo será explorado o desenvolvimento de um projeto de inovação, de uma espoleta eletrônica, elaborado a partir da parceria de duas empresas, sendo uma produtora de explosivos e uma empresa que desenvolve soluções tecnológicas para vários setores. Com isso, buscou-se analisar o papel desse projeto como mediador na construção de novas capacitações organizacionais. Com base na análise do caso, o estudo evidencia como a empresa produtora de explosivos foi impactada no nível organizacional em dimensões como cultura e comportamento, estratégia, gestão da inovação, bem como pessoas e estrutura organizacional.

Palavras-chave: projetos; inovação; capacitação organizacional; parceria. 


\section{INTRODUÇÃO}

A inovação é considerada por Verona e Ravasi (2003) como um processo de introdução de novas ideias à empresa para fornecer uma vantagem competitiva sustentável, aumentando seu desempenho. Paralelamente, Wang e Ahmed (2007) definem capacidades dinâmicas como o comportamento organizacional constantemente orientado a integrar, reconfigurar e recriar seus recursos e capacidades, melhorando e reconstruindo suas capacidades em resposta às mutações rápidas e constantes do ambiente para atingir e sustentar a vantagem competitiva.

Assim, dada a importância da temática, Davies e Brady (2016) discorrem sobre como projetos inovadores proporcionam novos desafios e experiências, impulsionando a construção de capacidades de inovação. Dessa forma, este artigo busca debater como projetos de inovação podem viabilizar o desenvolvimento de capacitações organizacionais em empresas. Para tanto, será explorado um projeto desenvolvido em parceria entre uma empresa produtora de explosivos e uma empresa que desenvolve soluções tecnológicas para o setor de mineração.

A concepção deste produto pode ser considerada como um projeto inovador porque, embora existam produtos similares em termos funcionais no mercado da mineração, a referida espoleta foi concebida por meio de um projeto próprio e com fraca correlação com projetos anteriores da empresa, assim como com recursos organizacionais já disponíveis. Assim, este artigo constituiu uma oportunidade para as empresas de buscarem adaptação propositada em relação à base de recursos existentes para alcançar o dinamismo do ambiente competitivo existente no mercado da mineração.

A figura 1 representa de forma simplificada a localização do problema de pesquisa estabelecido na temática proposta, pautando o desenvolvimento teórico e metodológico do estudo tratado nas seções seguintes.

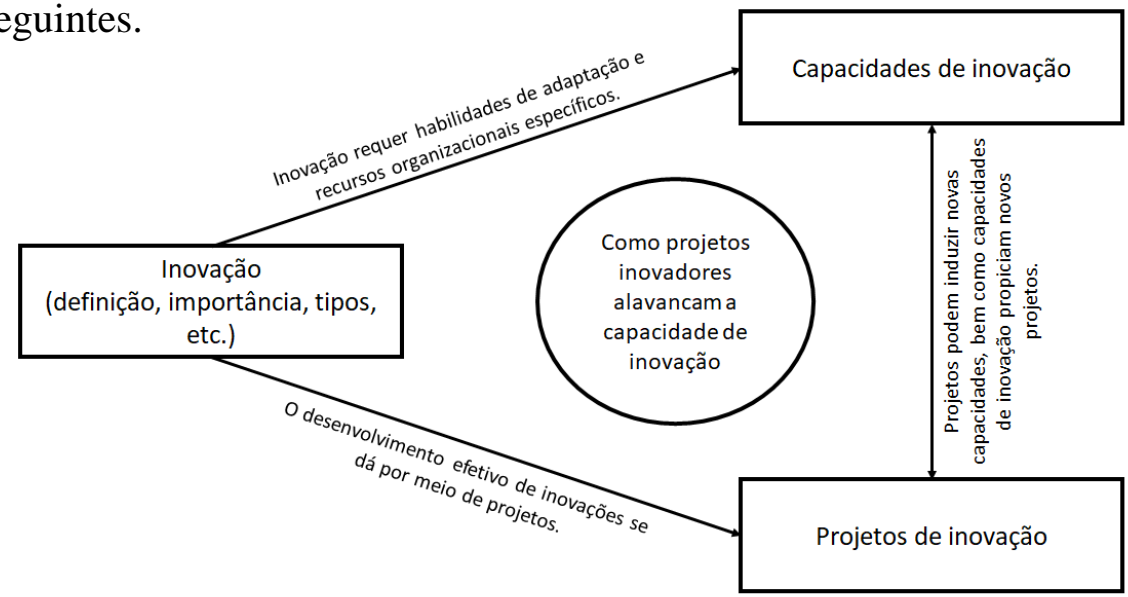

FIGURA 1 - Diagrama das temáticas envolvidas. Fonte: Elaborado pelos autores 


\section{REVISÃO TEÓRICA}

\subsection{Inovação}

Damanpour (1996) considera que inovações são concebidas como meios de mudança da organização, seja como respostas às mudanças do ambiente externo, seja como uma ação preventiva que influencie o ambiente. Infere que em um cenário de incerteza, todas empresas podem e devem responder positivamente em termos de inovação.

O Manual de Oslo (OCDE, 2018) define quatro tipos de inovações que encerram um amplo conjunto de mudanças nas atividades das empresas: inovações de produto, inovações de processo, inovações organizacionais e inovações de marketing. A inovação de produto pode se concretizar pela introdução ou melhoria de um bem ou serviço, pela incorporação de novos componentes, softwares ou aprimoramento na facilidade de uso ou outras características funcionais. A inovação de processo pode acontecer pela implementação de um método de produção ou distribuição novo ou significativamente melhorado. E as inovações organizacionais e de marketing incluem novas características organizacionais, novas formas comerciais da empresa, no layout e nas relações externas.

Tidd, Bessant e Pavitt (2005) consideram, no contexto das inovações de produto, que há uma dificuldade das empresas, sobretudo as menores, de competirem. A inovação é dirigida pela habilidade de identificar, promover conexões, de detectar oportunidades e tirar vantagem delas. Contudo, a inovação não se trata apenas de abrir novos mercados, mas também de maturar os já estabelecidos. E existem níveis diferentes de melhorias nos produtos e processos que vão desde mudanças incrementais até modificações radicais, transformando a forma como observamos e utilizamos os produtos.

\subsection{Capacidades de inovação}

Diante de um cenário de constantes mudanças, a habilidade de adaptação de processos e produtos como sinônimo de prosperidade nos negócios tornou-se importante para as empresas. Segundo Teece (2007) a existência de capacidades denominadas como "dinâmicas" está relacionada com a habilidade da organização em desenvolver novas estratégias mais rápido que os concorrentes por meio da reconfiguração de seus recursos de forma a gerar valor sob diferentes condições do ambiente externo. E que para economias abertas expostas a rápidas mudanças tecnológicas, a estrutura de capacidades dinâmicas destaca as competências 
organizacionais e estratégicas gerenciais que podem permitir a uma empresa obter vantagem competitiva e, em seguida, se transformar de forma semi-contínua para mantê-la.

Teece, Pisano e Shuen (1997) definem capacidades dinâmicas como a habilidade da firma de integrar, construir e reconfigurar competências internas e externas para lidar com ambientes em rápida mudança. Capacidades dinâmicas residem nos processos organizacionais estruturados pela posição (específica) dos ativos (tecnológicos, complementares, financeiros, de reputação, estruturais, institucionais, de mercado e limites organizacionais) e por sua evolução resultante do curso de ação de cada empresa. O foco está no processo pelo qual a empresa cria e renova suas competências, sempre em função do ambiente em que opera e no tripé: processos (rotinas e aprendizado), posições (ativos, estrutura de governança, base de consumidores e relações externas com fornecedores e parceiros) e trajetória (histórico de decisões e oportunidades tecnológicas e de mercado), para criar mudanças no mercado e reagir às mudanças externas.

\subsection{Projetos de inovação como fomentadores de capacitações organizacionais}

Projetos são ações planejadas ou esforços, com duração de tempo prevista, aplicados com o intuito de desenvolver produtos, serviços, melhorias ou qualquer outro tipo de resultado específico. Executados em todos os níveis organizacionais, os projetos são uma forma de cumprir as metas e objetivos almejados ou estipulados, de forma a gerar entregas, de várias naturezas, sendo elas tangíveis ou intangíveis. Assim, eles podem ser desenvolvidos de forma individual ou por um grupo de colaboradores de uma organização (PROJECT MANAGEMENT INSTITUTE - PMI, 2017).

Uma característica marcante de projetos inovadores é sua tendência em estar imerso a ambientes incertos e condições inesperadas. Estão focados em exploração e envolvem originalidade e complexidade. Cabe às organizações usufruir de capacidades dinâmicas determinadas a fim de elencar meios e maneiras para atuar em projetos dependendo das condições identificadas (DAVIES; BRADY, 2016).

Davies e Brady (2000) elucidam capacidade de projeto como sendo todo o conhecimento e vivência adquiridos para desenvolver, ajustar ou implantar projetos. Assim, novas capacidades de projetos podem também ser exploradas e impulsionadas pelas organizações com a utilização de um projeto de vanguarda. Frederiksen e Davies (2008) também corroboram com essa perspectiva de projetos de vanguarda, conceituando-os como sendo projetos ímpares e inéditos, desenvolvidos e implementados com o objetivo de diversificar, adentrar e explorar um novo 
mercado ou tecnologia. O estudo de Melo et al. (2020) traz um exemplo de como um projeto de vanguarda se manifestou como pivô da construção de um conjunto de capacidades de inovação que permitiram uma empresa industrial sistematizar práticas, estrutura e rotinas de inovação no nível organizacional.

Por fim, uma vez concluído com êxito, um determinado projeto é capaz de estimular mudanças e inovações, bem como gerar valor em vários âmbitos nas organizações. Em um cenário onde dinamismo nos negócios e ritmo acelerado são características marcantes, projetos bem geridos corroboram para que valor e benefícios organizacionais sejam entregues de forma consistente (PMI, 2017)

\section{METODOLOGIA}

Neste estudo, buscou-se elucidar características, parâmetros, ações e experiências que explicitem se e como esse projeto de inovação da espoleta eletrônica pode ser mediador da construção de capacidades de inovação na empresa produtora de explosivos.

Para tanto, com o objetivo de elencar pontos importantes para a análise da temática abordada, utilizou-se de um roteiro semiestruturado de entrevistas aplicadas para 04 integrantes da empresa produtora de explosivos e 01 integrante da empresa desenvolvedora de soluções tecnológicas, em que a duração média das conversas foi de 45 minutos. É válido ressaltar que todos tiveram participação importante no desenvolvimento do projeto da espoleta eletrônica e contribuíram com informações que posteriormente foram relacionadas com o conteúdo teórico explorado na literatura para análise dos resultados. Na empresa de explosivos foram ouvidos os supervisores de produção e de logística, o encarregado de manutenção e um engenheiro elétrico. Já na empresa de tecnologia foi ouvido um engenheiro mecânico, e que também era um dos sócios-proprietários.

Esse roteiro teve como base o quadro 1, a fim de reunir e agrupar o conjunto de elementos relacionados à construção de capacidade de inovação. É válido ressaltar que as perguntas foram utilizadas de acordo com a conduta e andamento da conversa, a fim de extrair o máximo de informações de forma natural. Com a comunicação fluida, e ocorrendo nas duas direções, a discussão tornou-se mais abrangente e direcionada aos tópicos pertinentes. 


\begin{tabular}{|c|c|c|}
\hline $\begin{array}{l}\text { Elementos relacionados à capacidade de inovação } \\
\text { da empresa }\end{array}$ & Grupo de autores & $\begin{array}{c}\text { Dimensão da } \\
\text { capacidade de inovação }\end{array}$ \\
\hline $\begin{array}{c}\text { Motivação para iniciar projetos de inovação e } \\
\text { melhoria }\end{array}$ & $\begin{array}{l}\text { Drucker (2003); Tidd, Bessant e Pavitt } \\
\text { (2005); McKelvie e Davidson (2009) }\end{array}$ & $\begin{array}{c}\text { Cultura e } \\
\text { Comportamento }\end{array}$ \\
\hline $\begin{array}{c}\text { A aceitação de desafios e de riscos é um traço da } \\
\text { cultura da empresa }\end{array}$ & $\begin{array}{l}\text { Christensen (1997); O'Connor (2008); } \\
\text { Lawson e Sam son (2001) }\end{array}$ & $\begin{array}{c}\text { Cultura e } \\
\text { Comportamento }\end{array}$ \\
\hline $\begin{array}{l}\text { A empresa compreende a necessidade de seguir } \\
\text { eficiente e ao mesmo tempo inovar em produtos e } \\
\text { serviços }\end{array}$ & $\begin{array}{c}\text { Adler et al (1999); Verona e Ravasi } \\
\text { (2003); Tidd, Bessant e Pavitt (2005); } \\
\text { Gibson e Birkinshaw (2004); Mom et } \\
\text { al. (2007) }\end{array}$ & $\begin{array}{l}\text { Cultura e } \\
\text { Comportamento }\end{array}$ \\
\hline $\begin{array}{l}\text { A empresa concede tempo e recursos ou estimula os } \\
\text { colaboradores criarem e compartilharem soluções } \\
\text { inovadoras }\end{array}$ & $\begin{array}{l}\text { Chesbrough (2006); Wang e Ahmed } \\
\text { (2007); Leifer et al (2002); Lawson e } \\
\text { Samson (2001) }\end{array}$ & $\begin{array}{c}\text { Cultura e } \\
\text { Comportamento }\end{array}$ \\
\hline $\begin{array}{l}\text { Identificar por meio dos clientes oportunidades de } \\
\text { melhoria }\end{array}$ & $\begin{array}{l}\text { Chesbrough (2006); Tidd, Bessant e } \\
\text { Pavitt (2005); Drucker (2003) }\end{array}$ & Estratégia \\
\hline Adaptação ao dinamismo do segmento & $\begin{array}{l}\text { Christensen (1997); O'Connor (2008); } \\
\text { Damanpour (1996); Tidd, Bessant e } \\
\text { Pavitt (2005); Teece (2007); Teece et } \\
\text { al. (1997); McKelvie e Davidson (2009) }\end{array}$ & Estratégia \\
\hline $\begin{array}{l}\text { Reconhecimento da importância da inovação para o } \\
\text { sucesso da organização no futuro }\end{array}$ & Manual de Oslo (2018); Drucker (2003) & Estratégia \\
\hline $\begin{array}{l}\text { Estratégia da empresa prevê recursos para projetos de } \\
\text { inovação e melhorias }\end{array}$ & $\begin{array}{l}\text { Teece (2007); Penrose (1959); } \\
\text { Eisenhardt et al. (2010) }\end{array}$ & Estratégia \\
\hline $\begin{array}{l}\text { A empresa compartilha experiências com outras } \\
\text { empresas e analisa os produtos e serviços da } \\
\text { concorrência }\end{array}$ & $\begin{array}{l}\text { Manual de Oslo (2018); Teece (2007); } \\
\text { Tidd, Bessant e Pavitt (2005); } \\
\text { Chesbrough (2006); Faccin, Balestrin } \\
\text { (2015); McKelvie e Davidson (2009) }\end{array}$ & Estratégia \\
\hline $\begin{array}{c}\text { Relações de parcerias e cooperação como chave para } \\
\text { o sucesso de projetos }\end{array}$ & $\begin{array}{l}\text { Cobo-Benita et al. (2016); Bruneel et } \\
\text { al., (2012); Faccin, Balestrin (2015) }\end{array}$ & Estratégia \\
\hline $\begin{array}{l}\text { Inovações em projetos são vistas como pré-requisitos } \\
\text { para sucesso competitivo }\end{array}$ & Gomes e Wojahn (2017) & Estratégia \\
\hline $\begin{array}{l}\text { Os projetos de inovação e melhoria já finalizados são } \\
\text { analisados em busca de lições para inovações futuras }\end{array}$ & $\begin{array}{c}\text { Christensen (1997); Tidd, Bessant e } \\
\text { Pavitt (2005); Lawson e Samson (2001) }\end{array}$ & Gestão da inovação \\
\hline Os controles gerenciais são flexíveis e pouco formais & $\begin{array}{c}\text { Leifer et al (2002); Lawson e Samson } \\
\text { (2001) }\end{array}$ & Gestão da inovação \\
\hline $\begin{array}{l}\text { A estrutura organizacional é mais propícia à } \\
\text { inovação e melhoria de novos produtos e processos }\end{array}$ & $\begin{array}{l}\text { Wang e Ahmed (2007); Lawson e } \\
\text { Samson (2001) }\end{array}$ & $\begin{array}{c}\text { Pessoas e estrutura } \\
\text { organizacional }\end{array}$ \\
\hline $\begin{array}{l}\text { A empresa busca desenvolver conhecimento e } \\
\text { habilidades dos empregados para obter vantagem } \\
\text { competitiva }\end{array}$ & $\begin{array}{l}\text { Teece (2007); Leifer et al (2002); } \\
\text { Lawson e Samson (2001) }\end{array}$ & $\begin{array}{l}\text { Pessoas e estrutura } \\
\text { organizacional }\end{array}$ \\
\hline $\begin{array}{l}\text { Os projetos são conduzidos por equipe } \\
\text { multidisciplinar onde cada perspectiva ajuda na } \\
\text { solução dos problemas }\end{array}$ & $\begin{array}{l}\text { Leifer et al (2002); Penrose (1959); } \\
\text { Lawson e Samson (2001) }\end{array}$ & $\begin{array}{l}\text { Pessoas e estrutura } \\
\text { organizacional }\end{array}$ \\
\hline $\begin{array}{l}\text { Busca-se continuamente o aprimoramento do } \\
\text { processo de produção }\end{array}$ & $\begin{array}{c}\text { Christensen (1997); Damanpour (1996); } \\
\text { Teece (2007); Teece et al. (1997); } \\
\text { McKelvie e Davidson (2009) } \\
\end{array}$ & $\begin{array}{l}\text { Pessoas e estrutura } \\
\text { organizacional }\end{array}$ \\
\hline $\begin{array}{c}\text { Há estrutura e definições claras sobre a gestão de } \\
\text { projetos }\end{array}$ & PMI (2007); Cooke-Davies et al. (2009) & $\begin{array}{c}\text { Pessoas e estrutura } \\
\text { organizacional }\end{array}$ \\
\hline $\begin{array}{l}\text { Projetos são reconhecidos como impulsionadores de } \\
\text { capacidades de inovação } \\
\end{array}$ & $\begin{array}{c}\text { Davies e Brady (2000); Davies e Brady } \\
\text { (2004); Davies e Brady (2016) }\end{array}$ & $\begin{array}{c}\text { Pessoas e estrutura } \\
\text { organizacional }\end{array}$ \\
\hline $\begin{array}{l}\text { A empresa dispõe de uma equipe própria de } \\
\text { especialistas para pesquisa e desenvolvimento de } \\
\text { novos produtos e processos }\end{array}$ & Penrose (1959); Chatenier et al (2010) & $\begin{array}{l}\text { Pessoas e estrutura } \\
\text { organizacional }\end{array}$ \\
\hline
\end{tabular}

QUADRO 1 - Quadro síntese. Fonte: Elaborado pelos autores. 


\section{RESULTADOS E DISCUSSÃO}

\subsection{O desenvolvimento da espoleta eletrônica}

A empresa de explosivos tinha, inicialmente, sua produção voltada para fogos de artifício. Com o aumento da concorrência proveniente da fabricação artesanal deste tipo de produto na cidade de Santo Antônio do Monte, a organização decidiu mudar o foco para atender, com produtos e serviços, o setor de mineração, participando ativamente de licitações. Em muitos casos, para participar dessas concorrências, a empresa verificou a necessidade de oferecer pacote de produtos e serviços que constasse a espoleta eletrônica. Embora o preço de cada espoleta eletrônica representasse pouco no valor final de faturamento, era um item indispensável para que a venda se efetivasse.

Neste contexto, surge o interesse em acrescentar no portfólio este item específico. Assim, durante uma feira do setor de mineração em 2012, observou-se que uma outra empresa, a desenvolvedora de soluções tecnológicas, apresentava um protótipo de uma espoleta eletrônica. O processo de desmonte de rochas prevê a perfuração de pontos na rocha e a posterior inserção dos explosivos em profundidades específicas para obtenção do minério desejado. Neste processo, o tempo de retardo entre a explosão que ocorre em cada um destes pontos torna-se um parâmetro a ser controlado. Se a detonação de cada ponto ocorrer de forma simultânea temos uma explosão, mas com baixa eficiência em termos da qualidade. Portanto, o que permite este desmonte na forma desejada é o controle de tempo. A partir deste momento, surgiu a ideia do desenvolvimento de uma parceria entre estas empresas.

É válido ressaltar que, naquela época, o produto não era novidade no mercado mundial, uma vez que já existiam 5 fabricantes no mundo. No entanto, a empresa de explosivos decidiu não depender deste componente importado. Além disso, nem sempre é possível ter acesso à informação completa em termos de funcionamento de uma espoleta eletrônica. Assim, nasceu a ideia de desenvolver uma espoleta eletrônica a partir do zero, com componentes adquiridos no comércio e o software utilizado desenvolvido pela empresa de tecnologia.

Ao final, o projeto ultrapassou as dificuldades técnicas inerentes à criação de um produto novo, e toda a equipe envolvida constatou que um desafio pode ser superado. Ou seja, ter concluído o projeto com êxito agora é um fator motivador para os colaboradores, enfatizando que estão em condições de encarar novos desafios. 


\subsection{Análise}

A análise dos resultados dessa pesquisa baseou-se majoritariamente no quadro 1, sendo este também o precursor para a elaboração do roteiro de entrevistas.

\subsubsection{Cultura e comportamento}

A cultura e comportamento dos colaboradores de uma empresa corroboram para que valores, princípios, comportamentos e ações sejam aplicados e desenvolvidos na rotina, de forma a guiar e motivar as atividades na empresa em diversos âmbitos. Nesse sentido, apesar dos desafios de adentrar em novo mercado, com uma nova tecnologia, contando com a participação de um parceiro, o desenvolvimento do projeto da espoleta eletrônica foi sinônimo de melhoria e motivação para novas capacidades organizacionais, como ressalta o entrevistado 1: "O legado principal foi na mudança de mindset dos colaboradores e da administração, percebendo que toda ideia precisa ser discutida e talvez desenvolvida. O custo deste projeto não foi aproveitado em outra iniciativa, mas ficou o sentimento de que novos desafios são possíveis, e que podem se tornar melhorias de processos ou produtos.".

Ao longo da conversa com os entrevistados, notou-se que o projeto da espoleta eletrônica rompeu as barreiras tradicionais na empresa de explosivos, em decorrência do compartilhamento de conhecimento e tecnologias em parceria com outra empresa. O sucesso desse desafio despertou a vontade dos colaboradores de estarem sempre em busca de melhorias para a fabricação de explosivos, sem perder o foco na qualidade e na segurança.

Somado ao exposto, observou-se que a estrutura organizacional e os processos gerenciais da produtora de explosivos não suportavam adequadamente projetos de inovação. Entretanto, a partir do sucesso do projeto da espoleta eletrônica, esta começou a cultivar uma cultura de inovação, de forma a estimular comportamentos e ideias inovadoras e criativas dos colaboradores, conforme retrata o entrevistado 3: “...depois disso já teve várias melhorias em outras partes, também com essa garantia que tem condição de melhorar alguma coisa, o pessoal dá ideias, e é sempre avaliado as ideias, as sugestões que aparecem.”.

Assim, a experiência proporcionada a partir do projeto de inovação da espoleta eletrônica gerou uma mudança de mentalidade em todos os setores da empresa. A gerência e a administração, ficaram mais receptivos e abertos a novas ideias, bem como os colaboradores do setor operacional exploram com maior frequência novas possibilidades de inovação. 


\subsubsection{Estratégia}

As estratégias são fundamentadas na avaliação das ameaças e oportunidades externas e da capacidade interna da empresa de responder a esses desafios e influenciar o ambiente externo. Novas oportunidades para inovar nas pequenas e médias empresas são fortemente influenciadas pelo sistema de inovação em que estão inseridas, e no setor de explosivos observa-se que são poucas as mudanças relevantes. Essa situação é refletida na fala do entrevistado 1: "No Brasil temos pouco campo para inovação. As grandes multinacionais do setor inovam mais. Lá fora inovação está mais desenvolvida. Mais copiam e se adaptam do que inovam no Brasil. A espoleta eletrônica criada é mais simples e mais eficiente, mas a ideia veio de fora”.

A empresa de explosivos aproveitou uma necessidade comercial como estratégia para atingir um novo mercado. A espoleta eletrônica passou a ser um diferencial nas vendas e para tanto foi preciso desenvolver competências para oferecer um novo produto e serviço que satisfizesse o cliente melhor do que os concorrentes.

Observou-se durante as entrevistas, com as pessoas com poder de decisão nas duas empresas parceiras, que houve facilidade de comunicação, velocidade na tomada de decisão, liberdade para executar mudanças no projeto, comprometimento da equipe e aceitação das novidades. Em acréscimo, não se observou falta de habilidade para desenvolver e gerenciar sistemas complexos.

Se uma empresa opta por uma estratégia defensiva, ela não quer correr o risco de ser a primeira a inovar, mas também não quer ser ultrapassada em termos tecnológicos. Se procura aprender com os erros de outras empresas para em seguida oferecer soluções mais eficientes. No caso da parceria estabelecida, observou-se uma estratégia imitativa para oferecer um produto semelhante ao já existente, muito embora tenha representado uma inovação para as empresas participantes no sentido de que o projeto se apoiava pouco em experiências, rotinas e projetos anteriores dessas empresas. Foi uma forma de estratégia inovadora e que pode ser implementada porque a empresa de explosivos já detinha um nicho de mercado.

\subsubsection{Gestão da inovação}

Observou-se a junção de conhecimentos distintos, porém complementares, entre os envolvidos na condução do projeto aproveitando melhor os recursos que a eletrônica dispunha para obter efetividade no processo, como ressalta o entrevistado 2: “ajudou em termos de conhecimento técnico para o Engenheiro de automação da empresa. Além disso, a parceria com a empresa 
produtora de explosivos rendeu um maior estreitamento e a possibilidade do desenvolvimento de novos produtos".

Somado a isso, controles gerenciais adotados foram mais flexíveis e menos formais, o que permitiu rapidez e agilidade no redesenho no projeto quando necessário, a realização de testes com explosivos de forma segura e que deu agilidade no desenvolvimento do projeto. A experiência obtida com o projeto ficou registrada e servirá de base para as lições aprendidas para inovações futuras.

\subsubsection{Pessoas e estrutura organizacional}

Cada empresa parceira desempenhou bem sua função para a concepção do projeto. Os colaboradores da empresa de tecnologia detinham know how para desenvolver o componente eletrônico e a equipe da empresa de explosivos para a realização dos testes necessários. Mesmo com a composição enxuta, as empresas aproveitaram o conhecimento e as habilidades dos colaboradores para obter vantagem competitiva, criando um produto sem similares no mercado nacional.

Embora a empresa de explosivos não dispusesse de uma equipe própria de especialistas para pesquisa e desenvolvimento de novos produtos e processos, a estrutura organizacional vigente facilitou sobremaneira a participação, motivação e colaboração dos envolvidos no projeto. Essa situação é refletida na fala do entrevistado 1: "A pirâmide organizacional por ser pequena exige a participação e o envolvimento de todos, diretoria, supervisão e engenharia. Todas as áreas são envolvidas quando se tem que desenvolver algo novo".

\section{CONSIDERAÇÕES FINAIS}

O projeto motivou a construção de capacidades de inovação em diferentes dimensões na empresa analisada, muito embora uma afirmação mais concreta devesse se dar após um período mais significativo e mediante o surgimento de outros projetos de relevância semelhante.

A inovação, embora não seja o foco do mercado estudado, teve no projeto um ambiente propício, com mudança de mindset e menos resistência a novas soluções. O responsável pela produção na empresa de explosivos ficou com mais argumentos para transitar entre os níveis organizacionais, mostrando que a empresa pode inovar com produtos e serviços. Rompeu-se a barreira comportamental em ambos (nível diretoria e chão de fábrica) com a decorrente 
sensibilização necessária para que um projeto tenha boa participação. Ao final, criou-se uma atmosfera propícia para a empresa partir para novas experiências.

Apesar do questionamento inicial ter sido respondido, uma dificuldade encontrada foi a recuperação de informações e experiências, uma vez que o projeto foi realizado há alguns anos e necessitou de um esforço da memória dos entrevistados para apontar e registrar o maior número de detalhes do projeto.

Notou-se evidências claras de um legado deixado pelo projeto da espoleta na empresa em termos de novas capacitações. Poucos meses depois da conclusão do projeto, foi necessário a troca de alguns painéis com Controladores Lógico Programável (PLC) e software dos controles da máquina que realiza o encartuchamento de emulsão. Nesse episódio, o supervisor de produção relatou ter observado uma certa apreensão dos operadores e colaboradores da planta. Entretanto, quando relembrou aos colaboradores sobre a experiência que haviam tido no projeto da espoleta, ficou nítida a mudança de comportamento, segundo o entrevistado: "Passaram a demonstrar entusiasmo, interesse e já queriam dar opiniões e sugestões..."

Por fim, este estudo apresentou resultados positivos, servindo como incentivador para que empresas projetos relevantes e tenham um objetivo explícito de auxiliar na construção de novas capacidades organizacionais para inovação, o que é cada vez mais importante em ambientes dinâmicos e competitivos do mundo atual. Como oportunidade para estudos futuros, abrem-se portas para estudar o potencial de projetos inovadores de maiores incertezas como indutores de capacidades de inovação, principalmente em empresas de médio porte.

\section{REFERÊECIAS}

ADLER, Paul S.; GOLDOFTAS, Barbara; LEVINE, David I. Flexibility versus efficiency? A case study of model changeovers in the Toyota production system. Organization Science, v. 10, n. 1, p. 43-68, 1999.

BRADY, Tim; DAVIES, Andrew. Building project capabilities: from exploratory to exploitative learning. Organization Studies, v. 25, n. 9, p. 1601-1621, 2004.

BRUNEEL, Johan et al. Improving the success of radical innovation projects within established firms: engaging employees across different hierarchal levels. Technology Analysis \& Strategic Management, v. 24, n. 9, p. 951$965,2012$.

CHESBROUGH, Henry. Open business models: How to thrive in the new innovation landscape. New York: Harvard, 2006.

CHATENIER, Elise du et al. Identification of competencies for professionals in open innovation teams. R\&d Management, v. 40, n. 3, p. 271-280, 2010.

CHRISTENSEN, Clayton M. The innovator's dilemma: when new technologies cause great firms to fail. New York: Harvard, 1997. 
COBO-BENITA, José Ramón et al. Innovation projects performance: Analyzing the impact of organizational characteristics. Journal of Business Research, v. 69, n. 4, p. 1357-1360, 2016.

COOKE-DAVIES, Terence J.; CRAWFORD, Lynn H.; LECHLER, Thomas G. Project management systems: moving project management from an operational to a strategic discipline. Project Management Journal, v. 40, n. 1, p. 110-123, 2009.

DAMANPOUR, Fariborz. Organizational complexity and innovation: developing and testing multiple contingency models. Management Science, v. 42, n. 5, p. 693-716, 1996.

DAVIES, Andrew; BRADY, Tim. Organisational capabilities and learning in complex product systems: towards repeatable solutions. Research Policy, v. 29, n. 7-8, p. 931-953, 2000.

DAVIES, Andrew; BRADY, Tim. Explicating the dynamics of project capabilities. International Journal of Project Management, v. 34, n. 2, p. 314-327, 2016.

DRUCKER, Peter Ferdinand. Inovação e espírito empreendedor (entrepreneurship): prática e princípios. Tradução de Carlos J. Malferrari. São Paulo: Pioneira Thomson, 2003.

EISENHARDT, Kathleen M.; FURR, Nathan R.; BINGHAM, Christopher B. CROSSROADSMicrofoundations of performance: Balancing efficiency and flexibility in dynamic environments. Organization Science, v. 21, n. 6, p. 1263-1273, 2010.

FACCIN, Kadigia; BALESTRIN, Alsones. Práticas colaborativas em P\&D: um estudo na indústria brasileira de semicondutores. RAM: revista de administração Mackenzie, v. 16, p. 190-219, 2015.

FREDERIKSEN, Lars; DAVIES, Andrew. Vanguards and ventures: projects as vehicles for corporate entrepreneurship. International Journal of Project Management, v. 26, n. 5, p. 487-496, 2008.

GIBSON, Cristina B.; BIRKINSHAW, Julian. The Antecedents, consequences, and mediating role of organizational ambidexterity. Academy of Management Journal, v. 47, n. 2, p. 209-226, 2004.

GOMES, Giancarlo; WOJAHN, Rafaele Matte. Organizational learning capability, innovation and performance: study in small and medium-sized enterprises (SMES). Revista de Administração (São Paulo), v. 52, p. 163-175, 2017.

LAWSON, Benn; SAMSON, Danny. Developing innovation capability in organisations: a dynamic capabilities approach. International Journal of Innovation Management, v. 5, n. 03, p. 377-400, 2001.

LEIFER, Richard; O'CONNOR, Gina Colarelli; RICE, Mark. A Implementação de inovação radical em empresas maduras. Revista de Administração de Empresas, v. 42, n. 2, p. 17-30, 2002.

MCKELVIE, Alexander; DAVIDSSON, Per. From resource base to dynamic capabilities: an investigation of new firms. British Journal of Management, v. 20, p. S63-S80, 2009.

MELO, Júlio Cézar Fonseca et al. From open innovation projects to open innovation project management capabilities: a process-based approach. International Journal of Project Management, v. 38, n. 5, p. 278-290, 2020 .

MOM, Tom J.M.; VAN DEN BOSCH, Frans A.J.; VOLBERDA, Henk W. Investigating managers' exploration and exploitation activities: the influence of top-down, bottom-up, and horizontal knowledge inflows. Journal of management studies, v. 44, n. 6, p. 910-931, 2007.

ORGANIZAÇÃO PARA COOPERAÇÃO E DESENVOLVIMENTO ECONÔMICO. Manual de Olso: proposta de diretrizes para coleta e interpretação de dados sobre inovação tecnológica. Tradução da Financiadora de Estudos e Projetos. Paris: OCED, 2018.

O'CONNOR, Gina Colarelli. Major innovation as a dynamic capability: a systems approach. Journal of Product Innovation Management, v. 25, n. 4, p. 313-330, 2008.

PENROSE, Edith; PENROSE, Edith Tilton. The Theory of the Growth of the Firm. Oxônia: Oxford university press, 1959. 
PMI, PMI. Um guia do conhecimento em gerenciamento de projetos (Guia PMBOK). In: Project Management Institute. 2017. p. 385-405.

TEECE, David J. Explicating dynamic capabilities: the nature and microfoundations of (sustainable) enterprise performance. Strategic Management Journal, v. 28, n. 13, p. 1319-1350, 2007.

TEECE, David J.; PISANO, Gary; SHUEN, Amy. Dynamic capabilities and strategic management. Strategic Management Journal, v. 18, n. 7, p. 509-533, 1997.

TIDD, Joe; BESSANT, John; PAVITT, Keith. Managing innovation: integrating technological, market and organizational change. 3rd.ed. Chichester: John Wiley, 2005.

VERONA, Gianmario; RAVASI, Davide. Unbundling dynamic capabilities: an exploratory study of continuous product innovation. Industrial and Corporate Change, v. 12, n. 3, p. 577-606, 2003.

WANG, Catherine L.; AHMED, Pervaiz K. Dynamic capabilities: a review and research agenda. International Journal of Management Reviews, v. 9, n. 1, p. 31-51, 2007. 